\title{
Segmented Poly(urethane-urea)s Synthesized Directly from Isocyanate-Terminated Prepolymers and Masked Diamines II. Kinetic and Mechanistic Study on Masking and Demasking Reaction
}

\author{
Hiroyuki Hanahata, $^{\dagger}$ Emiko Yamazaki, and Yoshiharu Kitahama ${ }^{\dagger \dagger}$ \\ Central Laboratory (Takatsuki), Asahi Chemical Industry Co., Ltd., \\ 11-7 Hacchonawate-cho, Takatsuki, Osaka 569, Japan. \\ (Received January 29, 1997)
}

\begin{abstract}
An attempt was made to clarify the mechanism of the reactions of acetone with propylenediamine (PDA) or ethylenediamine (EDA) for direct synthesis of poly(urethane-urea) (DSPUU reaction) by using the reaction products (masked diamines) and an isocyanate-terminated prepolymer. In the masking reaction of acetone with $\mathrm{PDA}$ at $40^{\circ} \mathrm{C}$, 1-( $N$-isopropylidene)propanediamine (1), 2-( $N$-isopropylidene)propanediamine $\left(1^{\prime}\right)$, 2,2-dimethyl-4-methylimidazolidine (3) as main product, $N, N^{\prime}$-diisopropylidenepropylenediamine (2) were formed in this order due to the dominant rate $\left(k_{30}=\right.$ $\left.3.0 \mathrm{~kg} \mathrm{~mol}^{-1} \mathrm{~min}^{-1}\right)$ of the water-catalyzed reaction to form (3) in addition to the slow rate $\left(k_{20}=3.2 \times 10^{-3} \mathrm{~kg} \mathrm{~mol}^{-1} \mathrm{~min}^{-1}\right)$ of (2). The concentration of $\left(\mathbf{1}^{\prime}\right)$ remained lower than (1) because of the steric hindrance of the methyl group of the former. The formation reactions of (1) and (2) were more acid-catalyzed than the reverse reactions, leading to shorter equilibrated time and larger molar fractions of these compounds. The reaction profiles for acetone-EDA were analogous except for lower molar fraction of 2,2-dimethylimidazolidine (6) and larger $N, N^{\prime}$-diisopropylideneethylenediamine. The rates of demasking reactions which are of importance in DSPUU reactions using masked EDAs were as follows; (i) the water- and acid-catalyzed ring opening reaction rate of (6), $k_{-30}$ and $k_{-3}=1.43$ and $0.26 \mathrm{~kg} \mathrm{~mol}^{-1} \mathrm{~min}^{-1}$ and (ii) the acid-catalyzed hydrolysis reaction rates of the ketimine groups, $k_{-1}=5.09$ and $k_{-2}=3.13 \mathrm{~kg}^{2} \mathrm{~mol}^{-2} \mathrm{~min}^{-1}$, respectively.

KEY WORDS Masked Diamines / Ketones / Propylenediamine / Ethylenediamine / Reaction Mechanism / Ketimine / Imidazolidine / Rate Constants /
\end{abstract}

In the previous paper, the direct synthesis of segmented poly(urethane-urea)s (DSPUU reaction) was successful by using an isocyanate-terminated prepolymer (ITPP) based on 4,4'-methylenediphenyldiisocyanate (MDI) and poly(tetramethyleneoxide) (PTMO, $\left.\bar{M}_{n}=2010\right)$, and the reaction products from acetone and ethylenediamine (EDA) (masked EDA) consisting of $N$-isopropylideneethylenediamine, $N, N^{\prime}$-diisopropylideneethylenediamine, 2,2-dimethylimidazolidine as main product, water, and the unreacted raw materials. ${ }^{1}$ The emphasis was laid on the methodological study to eliminate the by-product (Urea II) arising from the reaction of an isocyanate (NCO) group with water catalyzed by the ketimine and the imino groups. Acetic acid played a significant roll for vanishing Urea II, leading to the quantitative yield of the desired urea group, Urea I.

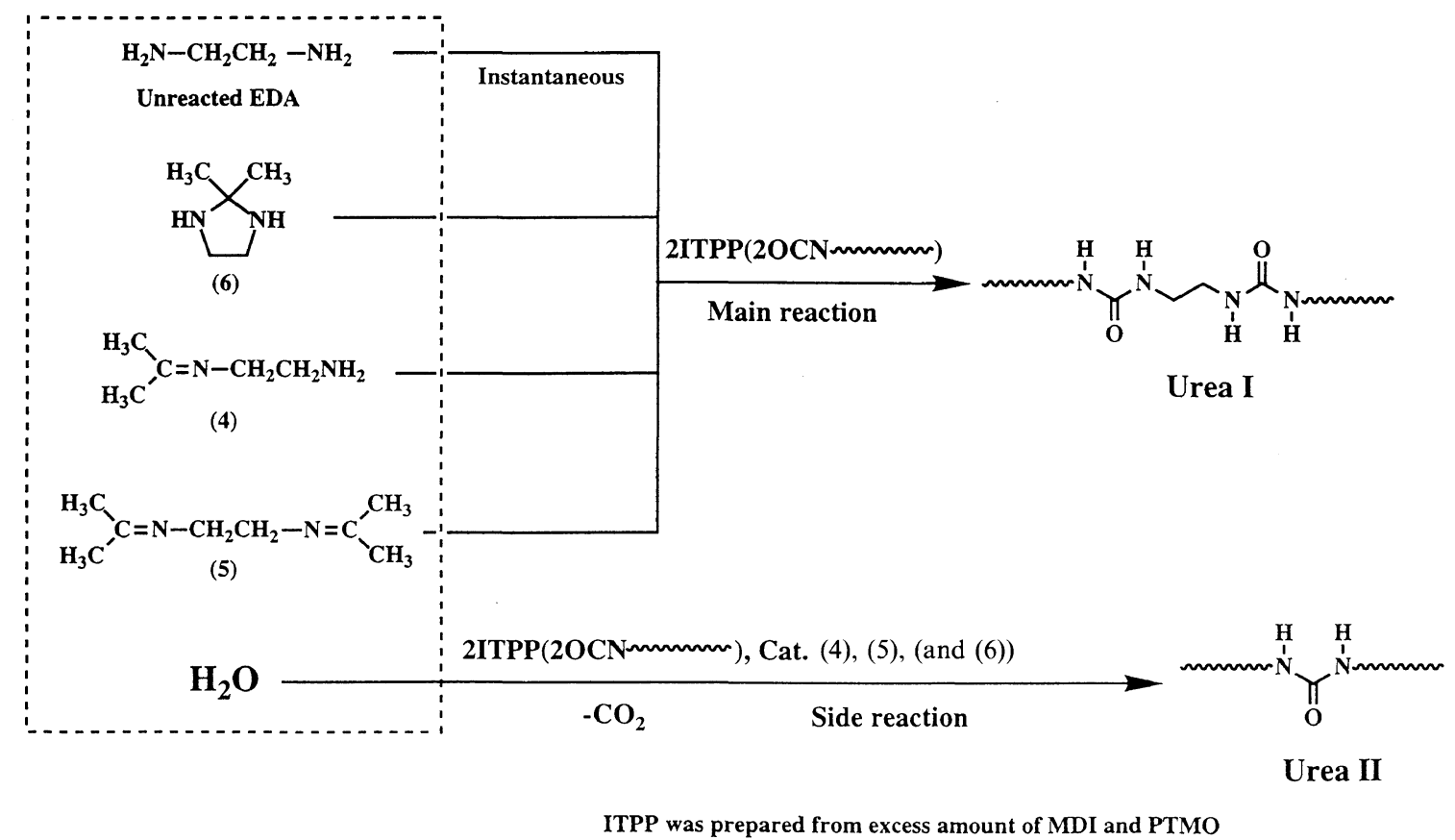

Scheme 1. Schematic representation of one of the reaction pathways ('direct' reactions) of DSPUU reactions in the absence of an acid.

$\dagger$ To whom correspondence should be addressed.

${ }^{\dagger \dagger}$ Present address: Japan Elastomer Co., Ltd., Oaza Nakanosu 2, Oita 870-01, Japan. 


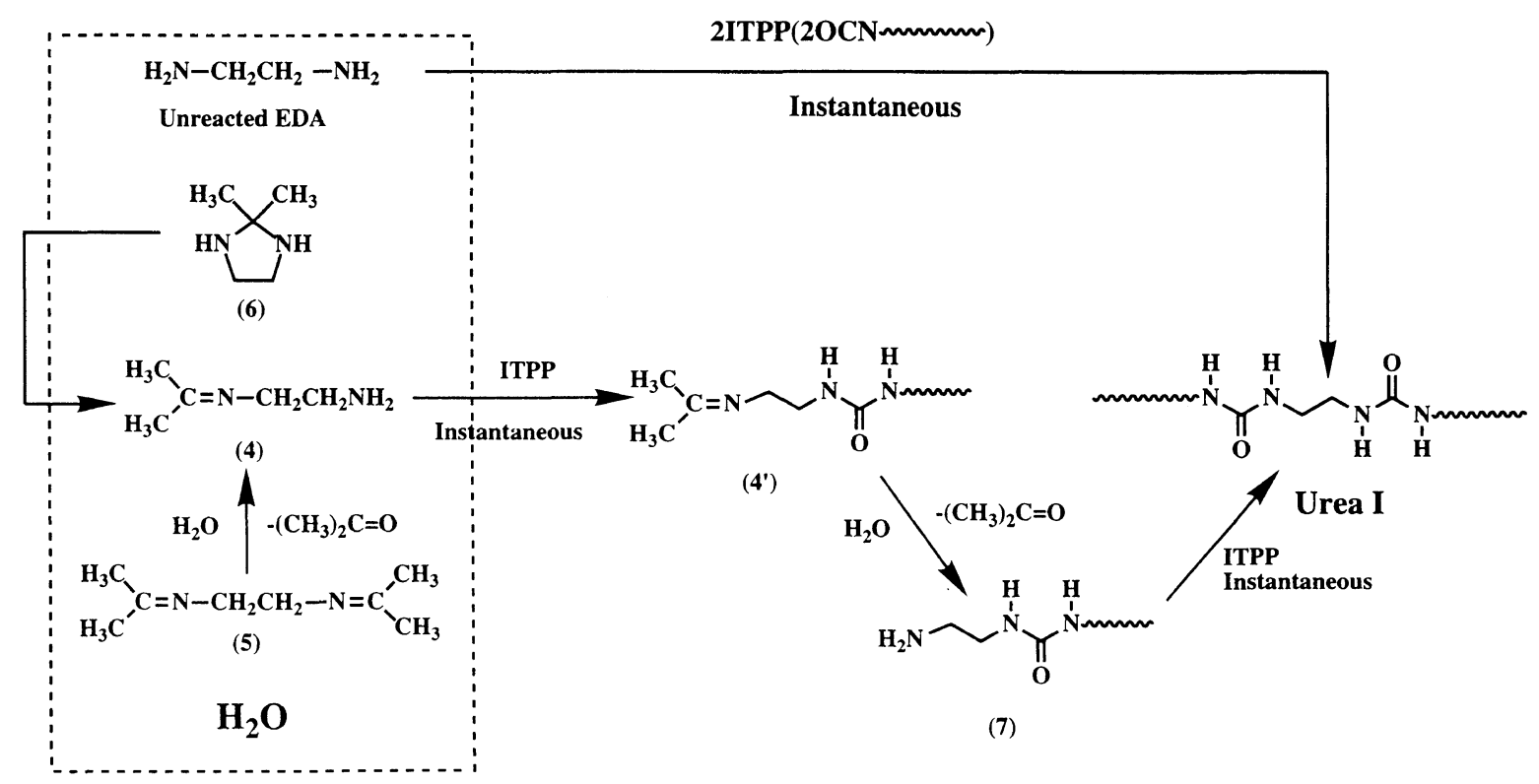

ITPP was prepared from excess amount of MDI and PTMO

Scheme 2. Another kind of possible reaction pathways ('demasking' reactions) of DSPUU reactions in the absence of an acid.

One kind of reactions taking place in the course of DSPUU reactions in the absence of an acid falls into the category of the 'direct' reactions, that is, the reactions of the NCO-terminated prepolymer (ITPP) with the ketimine and the imino groups (Scheme 1). ${ }^{1,2}$ As a side reaction the reaction of ITPP with water catalyzed by the above ketimine and imino groups take place simultaneously.

Another kind of probable reactions is well-known 'demasking' reactions. The hydrolysis reactions of the above monoketimine and the diketimine as well as the ring opening reaction of the imidazolidine corresponds to this category ${ }^{1,2}$ (Scheme 2).

However, due to lack of kinetic information about all the elementary reactions falling in the two kinds of the categories, it is not known which reactions actually occur in DSPUU reactions dominantly or simultaneously. Furthermore the mechanistic roll of the acid to eliminate the by-product is of course left untouched, being far from clarifying the mechanism of the DSPUU reaction.

Therefore, for the purpose of attaining the goal to clarify the complicated DSPUU reaction mechanism, we attempted in this paper to elucidate the mechanism of the reactions of acetone with the commercially important diamines such as propylenediamine (PDA) and EDA from the kinetic view point by comparing the concentration changes of the reaction products formed during the reactions by ${ }^{13} \mathrm{C}$ NMR analysis, with those calculated by solving the rate equations for each elementary reaction. In the course of this comparison the rate and acid-catalyst constants, in particular, those relating to the demasking reactions were estimated, which will give an essential basis for clarifying the DSPUU reaction mechanism.

\section{EXPERIMENTAL}

\section{Materials}

Extra pure grade $(99.5 \%)$ ketones such as acetone, ethyl methyl ketone, methyl propyl ketone, isopropyl methyl ketone, diethyl ketone, dipropyl ketone, diisopropyl ketone, and amines including propylenediamine (PDA) and ethylenediamine (EDA), all of which were supplied by Wako Pure Chemical Industries, Ltd. (Osaka, Japan), were distilled before use. Deuteriochloroform $(99.95 \%)$ and deuterated acetone $(99.95 \%)$, which were also purchased from the same manufacturer, were used as received.

\section{Reactions of Various Ketones with PDA or EDA}

The reactions of various ketones listed in Table I with PDA in deuterated chloroform (for the preparation of KP1-7 samples) and the reactions of acetone (contained $c a$. $20 \mathrm{~mol} \%$ deuterated acetone used as a locking signal solvent) with PDA or EDA (AP1-7, AE1-4) were directly carried out in a NMR sample tube $(5 \mathrm{~mm} \phi)$. The reaction conditions are also compiled in Table I. The preparation procedure for AP2 was described below as a typical example; $0.341 \mathrm{~g}\left(5.9 \times 10^{-3} \mathrm{~mol}\right)$ of acetone and $0.085 \mathrm{~g}\left(1.3 \times 10^{-3} \mathrm{~mol}\right)$ of deuterated acetone and $0.148 \mathrm{~g}\left(2.0 \times 10^{-3} \mathrm{~mol}\right)$ of PDA were placed into a tightly sealed NMR sample tube $(5 \mathrm{~mm} \phi)$ and heated at $40^{\circ} \mathrm{C}$ for $2 \mathrm{~h}$. The reaction product at an elapsed reaction time was periodically subjected to ${ }^{13} \mathrm{C}$ NMR measurement under the operating conditions described in Measurements and ANALYSES section.

\section{MEASUREMENTS AND ANALYSES}

Several attempts were made by using FT-IR, ${ }^{1} \mathrm{H}$ and ${ }^{13} \mathrm{C}$ NMR to follow the reactions of various ketones with the diamines. Although the FT-IR method was found suitable for detecting $\mathrm{C}=\mathrm{O}$ stretching of acetone $\left(1709 \mathrm{~cm}^{-1}\right)$ and $\mathrm{C}=\mathrm{N}$ stretching of a ketimine group 
H. Hanahata, E. Yamazaki, and Y. Kitahama

Table I. Reaction conditions of various ketones with propylenediamine (PDA) or ethylenediamine (EDA)

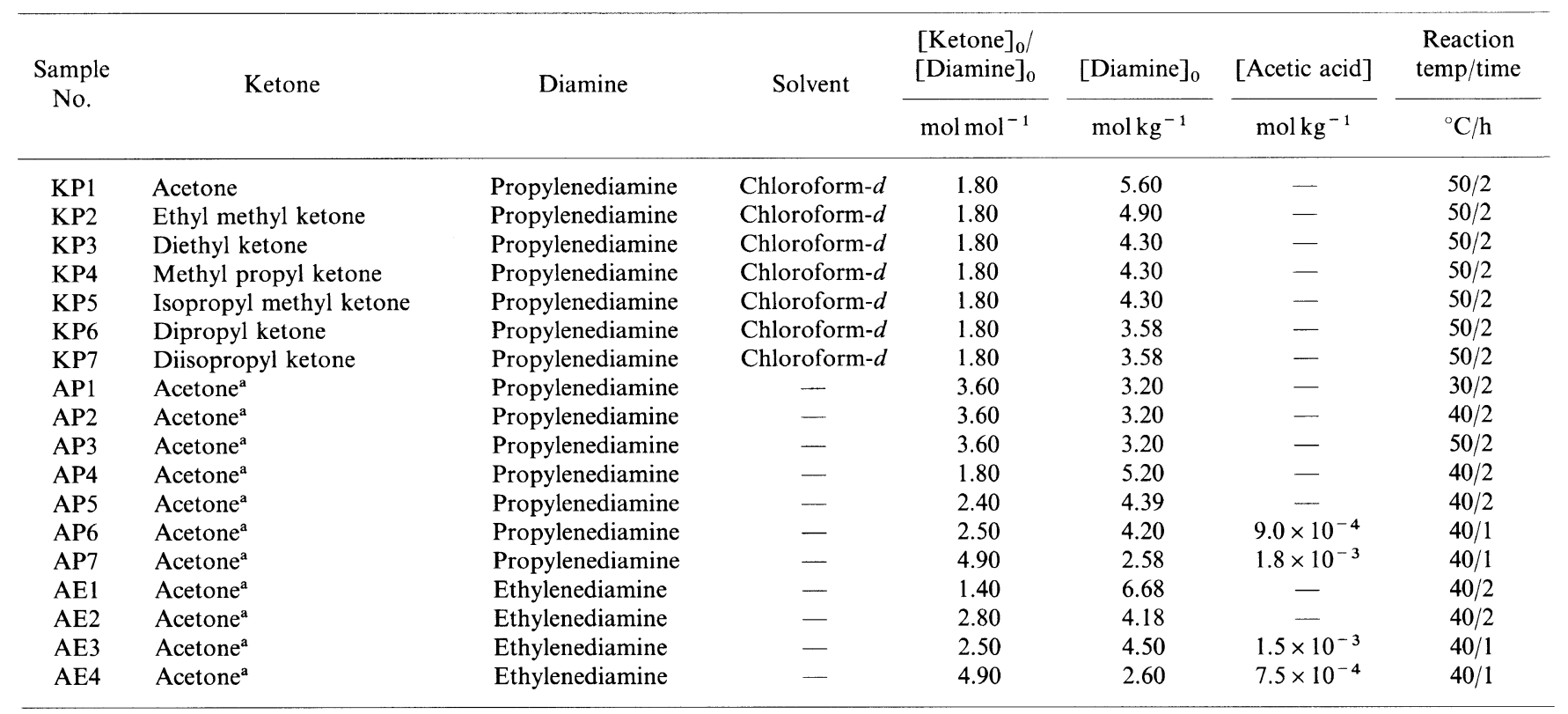

${ }^{\mathrm{a}}[$ Acetone $] /\left[\right.$ Acetone- $\left.d_{6}\right]=5 / 1\left(\mathrm{~mol} \mathrm{~mol}^{-1}\right)$ for the NMR measurement.

$\left(1662 \mathrm{~cm}^{-1}\right)$, a characteristic absorption of an imino group of an imidazolidine $\left(1600 \mathrm{~cm}^{-1}\right)$ overlapped with other peaks, giving erroneous estimation and thus failing in the quantitative following of these compounds by FT-IR. Carbinolamine intermediates which should be formed during a formation pathway of the ketimine group and its reverse reaction ${ }^{3}$ could not be detected even by the time-resolved FT-IR, presumably because of the low steady-state concentration of the intermediate (it was not accumulating at detectable concentrations).

When the reaction products were monitored by ${ }^{1} \mathrm{H}$ NMR, the broad peak of the NH group of PDA at around $1.8 \mathrm{ppm}$ moved toward the lower magnetic field as the reaction proceeds and inevitably overlapped with other peaks, also giving incorrect intensity values of the peaks. Contrary to the above FT-IR and ${ }^{1} \mathrm{H}$ NMR measurements, ${ }^{13} \mathrm{C}$ NMR spectra were free from these problems and capable of following the reactions by monitoring intensity changes of methylene or methyne carbon of PDA.

The ${ }^{13} \mathrm{C}$ NMR operating conditions for the reactions from various ketones with PDA (KP1-7) and those from acetone with PDA (AP1-7) or EDA (AE1-4) were as follows on a JEOL GSX-400 spectrometer; complete decoupling mode; delay time $5 \mathrm{~s}$; acquisition time $0.655 \mathrm{~s}$; pulse width $5.5 \mathrm{~ms}\left(45^{\circ}\right.$ pulse $)$; accumulation 96 times. Note that the delay time was found enough and appropriate to be $5 \mathrm{~s}$ by a preliminary selection test monitoring the peak intensities of methylene or methine carbons of the reaction products.

\section{RATE EQUATIONS}

The rate equations for the reactions of acetone with PDA in the presence of an acid catalyst are given by eq $1-6$ referred to our results on the reaction products ${ }^{2}$ and acid-catalysis of the analogous reactions of ketones with monoamines in water ${ }^{4}$ as well as acid and water catalysis of the imidazolidines. ${ }^{5}$ It should be noted that the rate and catalyst constants with respect to the ketimine formation reactions and the reverse reactions in those equations may be regarded as those of the dehydration reactions and the hydrolysis reactions of carbinolamine intermediates, respectively by ab initio MO method. ${ }^{6}$

The rates of decrease in the concentrations of PDA and acetone can be expressed in eq 1 and 2, respectively, considering the asymmetrical structure of PDA.

$$
\begin{aligned}
- & \mathrm{d}[\mathrm{PDA}] / \mathrm{d} t=\left(k_{10}+k_{1}\left[\mathrm{H}^{+}\right]\right)[\mathrm{PDA}][\text { acetone }] \\
& -\left(k_{-10}+k_{-1}\left[\mathrm{H}^{+}\right]\right)[(\mathbf{1})]\left[\mathrm{H}_{2} \mathrm{O}\right] \\
& +\left(k_{10}^{\prime}+k_{1}^{\prime}\left[\mathrm{H}^{+}\right]\right)[\mathrm{PDA}][\text { acetone }] \\
& -\left(k_{-10}^{\prime}+k_{-1}^{\prime}\left[\mathrm{H}^{+}\right]\right)\left[\left(\mathbf{1}^{\prime}\right)\right]\left[\mathrm{H}_{2} \mathrm{O}\right] \\
- & \mathrm{d}[\text { acetone }] / \mathrm{d} t=\left(k_{10}+k_{1}\left[\mathrm{H}^{+}\right]\right)[\mathrm{PDA}][\text { acetone }] \\
& +\left(k_{20}+k_{2}\left[\mathrm{H}^{+}\right]\right)[(\mathbf{1})][\text { acetone }] \\
& -\left(k_{-10}+k_{-1}\left[\mathrm{H}^{+}\right]\right)[(\mathbf{1})]\left[\mathrm{H}_{2} \mathrm{O}\right] \\
& -\left(k_{-20}+k_{-2}\left[\mathrm{H}^{+}\right]\right)[(2)]\left[\mathrm{H}_{2} \mathrm{O}\right] \\
& +\left(k_{10}^{\prime}+k_{1}^{\prime}\left[\mathrm{H}^{+}\right]\right)[\mathrm{PDA}][\text { acetone }] \\
& +\left(k_{20}^{\prime}+k_{2}^{\prime}\left[\mathrm{H}^{+}\right]\right)\left[\left(\mathbf{1}^{\prime}\right)\right][\text { acetone }] \\
& -\left(k_{-10}^{\prime}+k_{-1}^{\prime}\left[\mathrm{H}^{+}\right]\right)\left[\left(\mathbf{1}^{\prime}\right)\right]\left[\mathrm{H}_{2} \mathrm{O}\right] \\
& -\left(k_{20}^{\prime}+k_{-2}^{\prime}\left[\mathrm{H}^{+}\right]\right)[(\mathbf{2})]\left[\mathrm{H}_{2} \mathrm{O}\right]
\end{aligned}
$$

where $k_{10}$ and $k_{20}$ represent the rate constants of the dehydration reactions to form ketimine group of 1- $(N$ isopropylidene)propanediamine (1) and 1,2-diisopropylidenepropanediamine (2), respectively. The rate constants of $k_{-10}$ and $k_{-20}$ are those for the reverse reactions (Scheme 3 ). The values of $k_{10}^{\prime}, k_{20}^{\prime}, k_{-10}^{\prime}$, and $k_{-20}^{\prime}$ are the rate constants of the similar reactions to form (1') and (2) via (1') and their reverse reactions. The values of $k_{1}, k_{2}, k_{-1}$, and $k_{-2}\left(k_{1}^{\prime}, k_{2}^{\prime}, k_{-1}^{\prime}\right.$, and $\left.k_{-2}^{\prime}\right)$ are the catalyst constants for the corresponding reactions. Since acetic acid is ionized perfectly by the largely excess concentration of the amino groups of EDA $\left(\mathrm{H}_{2} \mathrm{~N}-\mathrm{R}\right){ }^{7}$ the concentration of the proton, $\left[\mathrm{H}^{+}\right]$in the above equations should be replaced by the concentration of 
$\mathrm{H}_{3}^{+} \mathrm{N}-\mathrm{R}$ whose acidity is as strong as that of $\mathrm{H}_{3}^{+} \mathrm{O}$ in an aqueous solution. Hence the concentration of acetic acid added is equivalent to that of $\mathrm{H}_{3}^{+} \mathrm{N}-\mathrm{R}$.

Similarly, the rates of decrease in the concentrations of (1), (1'), (2), 2,2-dimethyl-4-methylimidazolidine (3), and water, all of which are subject to acid-catalysis ${ }^{4}$ can be expressed in the eq 3-6, respectively. In these equations the water and acid catalyzed reactions of (3) are considered..$^{4,5}$

$$
\begin{aligned}
& -\mathrm{d}[(\mathbf{1})] / \mathrm{d} t=\left(k_{-10}+k_{-1}\left[\mathrm{H}^{+}\right]\right)[(\mathbf{1})]\left[\mathrm{H}_{2} \mathrm{O}\right] \\
& +\left(k_{20}+k_{2}\left[\mathrm{H}^{+}\right]\right)[(\mathbf{1})][\text { acetone }] \\
& +\left(k_{30}\left[\mathrm{H}_{2} \mathrm{O}\right]+k_{3}\left[\mathrm{H}^{+}\right]\right)[(\mathbf{1})] \\
& -\left(k_{10}+k_{1}\left[\mathrm{H}^{+}\right]\right)[\mathrm{PDA}][\text { acetone] } \\
& -\left(k_{-20}+k_{-2}\left[\mathrm{H}^{+}\right]\right)[(2)]\left[\mathrm{H}_{2} \mathrm{O}\right] \\
& -\left(k_{-30}\left[\mathrm{H}_{2} \mathrm{O}\right]+k_{-3}\left[\mathrm{H}^{+}\right]\right)[(3)] \\
& -\mathrm{d}\left[\left(\mathbf{1}^{\prime}\right)\right] / \mathrm{d} t=\left(k_{-10}^{\prime}+k_{-1}^{\prime}\left[\mathrm{H}^{+}\right]\right)\left[\left(\mathbf{1}^{\prime}\right)\right]\left[\mathrm{H}_{2} \mathrm{O}\right] \\
& +\left(k_{20}^{\prime}+k_{2}^{\prime}\left[\mathrm{H}^{+}\right]\right)\left[\left(\mathbf{1}^{\prime}\right)\right][\text { acetone }] \\
& +\left(k_{30}^{\prime}\left[\mathrm{H}_{2} \mathrm{O}\right]+k_{3}^{\prime}\left[\mathrm{H}^{+}\right]\right)\left[\left(\mathbf{1}^{\prime}\right)\right] \\
& -\left(k_{10}^{\prime}+k_{1}^{\prime}\left[\mathrm{H}^{+}\right]\right)[\mathrm{PDA}][\text { acetone] } \\
& -\left(k_{-20}^{\prime}+k_{-2}^{\prime}\left[\mathrm{H}^{+}\right]\right)[(2)]\left[\mathrm{H}_{2} \mathrm{O}\right] \\
& -\left(k_{-30}^{\prime}\left[\mathrm{H}_{2} \mathrm{O}\right]+k_{-3}^{\prime}\left[\mathrm{H}^{+}\right]\right)[(3)] \\
& -\mathrm{d}[(2)] / \mathrm{d} t=\left(k_{-20}+k_{-2}\left[\mathrm{H}^{+}\right]\right)[(2)]\left[\mathrm{H}_{2} \mathrm{O}\right] \\
& +\left(k_{20}+k_{2}\left[\mathrm{H}^{+}\right]\right)[(\mathbf{1})][\text { acetone }] \\
& -\left(k_{-20}^{\prime}+k_{-2}^{\prime}\left[\mathrm{H}^{+}\right]\right)[(2)]\left[\mathrm{H}_{2} \mathrm{O}\right] \\
& -\left(k_{20}^{\prime}+k_{2}^{\prime}\left[\mathrm{H}^{+}\right]\right)\left[\left(\mathbf{1}^{\prime}\right)\right][\text { acetone }] \\
& -\mathrm{d}[(\mathbf{3})] / \mathrm{d} t=\left(k_{-30}\left[\mathrm{H}_{2} \mathrm{O}\right]+k_{-3}\left[\mathrm{H}^{+}\right]\right)[(3)] \\
& -\left(k_{30}\left[\mathrm{H}_{2} \mathrm{O}\right]+k_{3}\left[\mathrm{H}^{+}\right]\right)[(1)] \\
& +\left(k_{-30}^{\prime}\left[\mathrm{H}_{2} \mathrm{O}\right]+k_{-3}^{\prime}\left[\mathrm{H}^{+}\right]\right)[(3)] \\
& -\left(k_{30}^{\prime}\left[\mathrm{H}_{2} \mathrm{O}\right]\right. \\
& \left.-k_{3}^{\prime}\left[\mathrm{H}^{+}\right]\right)\left[\left(\mathbf{1}^{\prime}\right)\right] \\
& -\mathrm{d}\left[\mathrm{H}_{2} \mathrm{O}\right] / \mathrm{d} t=\left(k_{-10}+k_{-1}\left[\mathrm{H}^{+}\right]\right)[(\mathbf{1})]\left[\mathrm{H}_{2} \mathrm{O}\right] \\
& +\left(k_{-20}+k_{-2}\left[\mathrm{H}^{+}\right]\right)[(2)]\left[\mathrm{H}_{2} \mathrm{O}\right] \\
& -\left(k_{10}+k_{1}\left[\mathrm{H}^{+}\right]\right)[\mathrm{PDA}][\text { acetone] } \\
& -\left(k_{20}+k_{2}\left[\mathrm{H}^{+}\right]\right)[(\mathbf{1})][\text { acetone }] \\
& +\left(k_{-10}^{\prime}+k_{-1}^{\prime}\left[\mathrm{H}^{+}\right]\right)\left[\left(\mathbf{1}^{\prime}\right)\right]\left[\mathrm{H}_{2} \mathrm{O}\right] \\
& +\left(k_{-20}^{\prime}+k_{-2}^{\prime}\left[\mathrm{H}^{+}\right]\right)[(2)]\left[\mathrm{H}_{2} \mathrm{O}\right] \\
& -\left(k_{10}^{\prime}+k_{1}^{\prime}\left[\mathrm{H}^{+}\right]\right)[\mathrm{PDA}][\text { acetone }] \\
& -\left(k_{20}^{\prime}+k_{2}^{\prime}\left[\mathrm{H}^{+}\right]\right)\left[\left(\mathbf{1}^{\prime}\right)\right][\text { acetone] }
\end{aligned}
$$

where the rate and catalyst constants in these equations correspond to those in Scheme 3.

In the case of the reaction using EDA the rate equations are simplified because of the symmetrical structure of EDA as eq 7-12. Compounds (4), (5), and (6), respectively denote $N$-isopropylideneethylenediamine, $N, N^{\prime}$ diisopropylideneethylenediamine, and 2,2-dimethylimidazolidine.

$$
\begin{aligned}
& -\mathrm{d}[\mathrm{EDA}] / \mathrm{d} t=2\left(k_{10}+k_{1}\left[\mathrm{H}^{+}\right]\right)[\mathrm{EDA}][\text { acetone }] \\
& -\left(k_{-10}+k_{-1}\left[\mathrm{H}^{+}\right]\right)[(4)]\left[\mathrm{H}_{2} \mathrm{O}\right] \\
& -\mathrm{d}[\text { acetone }] / \mathrm{d} t=2\left(k_{10}+k_{1}\left[\mathrm{H}^{+}\right]\right)[\mathrm{EDA}][\text { acetone }] \\
& \quad+\left(k_{20}+k_{2}\left[\mathrm{H}^{+}\right]\right)[(4)][\text { acetone }] \\
& -\left(k_{-10}+k_{-1}\left[\mathrm{H}^{+}\right]\right)[(4)]\left[\mathrm{H}_{2} \mathrm{O}\right]
\end{aligned}
$$

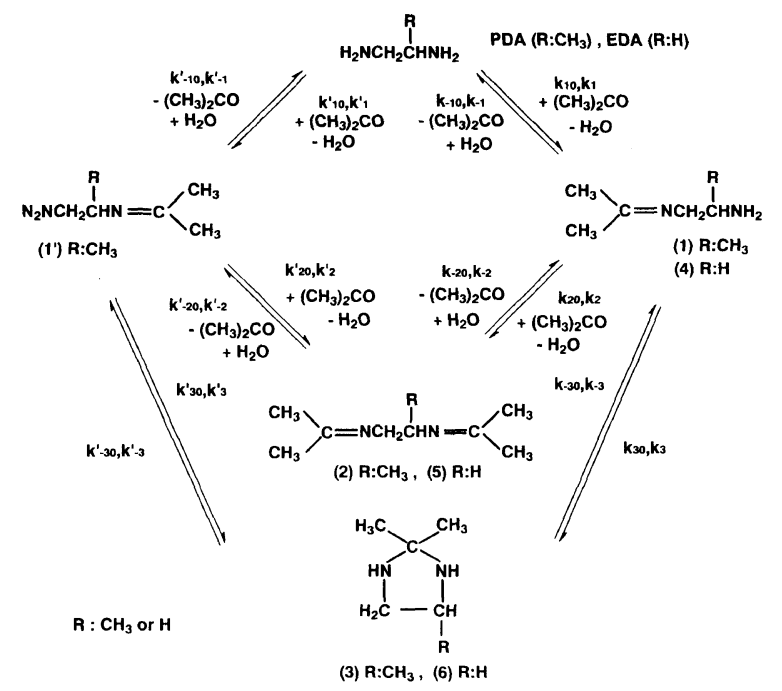

Scheme 3. Elementary reactions constituting reactions of acetone with propylenediamine or ethylenediamine.

$$
\begin{aligned}
& -2\left(k_{-20}+k_{-2}\left[\mathrm{H}^{+}\right]\right)[(5)]\left[\mathrm{H}_{2} \mathrm{O}\right] \\
- & \mathrm{d}[(\mathbf{4})] / \mathrm{d} t=\left(k_{-10}+k_{-1}\left[\mathrm{H}^{+}\right]\right)[(4)]\left[\mathrm{H}_{2} \mathrm{O}\right] \\
& +\left(k_{20}+k_{2}\left[\mathrm{H}^{+}\right]\right)[(4)][\text { acetone }] \\
& +\left(k_{30}\left[\mathrm{H}_{2} \mathrm{O}\right]+k_{-3}\left[\mathrm{H}^{+}\right]\right)[(6)] \\
& -2\left(k_{10}+k_{1}\left[\mathrm{H}^{+}\right]\right)[\mathrm{EDA}][\text { acetone }] \\
& -2\left(k_{-20}+k_{-2}\left[\mathrm{H}^{+}\right]\right)[(5)]\left[\mathrm{H}_{2} \mathrm{O}\right] \\
& -\left(k_{-30}\left[\mathrm{H}_{2} \mathrm{O}\right]+k_{-3}\left[\mathrm{H}^{+}\right]\right)[(6)] \\
- & \mathrm{d}[(5)] / \mathrm{d} t=2\left(k_{-20}+k_{-2}\left[\mathrm{H}^{+}\right]\right)[(5)]\left[\mathrm{H}_{2} \mathrm{O}\right] \\
& -\left(k_{20}+k_{2}\left[\mathrm{H}^{+}\right]\right)[(4)][\text { acetone }] \\
- & \mathrm{d}[(6)] / \mathrm{d} t=\left(k_{-30}\left[\mathrm{H}_{2} \mathrm{O}\right]+k_{-3}\left[\mathrm{H}^{+}\right]\right)[(6)] \\
& -\left(k_{30}\left[\mathrm{H}_{2} \mathrm{O}_{+}+k_{3}\left[\mathrm{H}^{+}\right]\right)[(4)]\right. \\
- & \mathrm{d}\left[\mathrm{H}_{2} \mathrm{O}\right] / \mathrm{d} t=\left(k_{-10}+k_{-1}\left[\mathrm{H}^{+}\right]\right)[(4)]\left[\mathrm{H}_{2} \mathrm{O}\right] \\
& +2\left(k_{-20}+k_{-2}\left[\mathrm{H}^{+}\right]\right)[(5)]\left[\mathrm{H}_{2} \mathrm{O}\right] \\
& -2\left(k_{10}+k_{1}\left[\mathrm{H}^{+}\right]\right)[\mathrm{EDA}][\text { acetone }] \\
& -\left(k_{20}+k_{2}\left[\mathrm{H}^{+}\right]\right)[(4)][\text { acetone }]
\end{aligned}
$$

The twelve rate constants such as a set of $k_{10}, k_{-10}, k_{20}$, $k_{-20}, k_{30}$, and $k_{-30}$ as well as a set of $k_{10}^{\prime}, k_{-10}^{\prime}, k_{20}^{\prime}$, $k_{-20}^{\prime}, k_{30}^{\prime}$, and $k_{-30}^{\prime}$ were estimated as follows in a two-step procedure, utilizing the representative data of the AP4 reaction (acetone with PDA in the absence of an acid catalyst). The rate constants, $k_{10}, k_{-10}, k_{30}$, and $k_{-30}$ in addition to $k_{10}^{\prime}, k_{-10}^{\prime}, k_{30}^{\prime}$, and $k_{-30}^{\prime}$ were determined by fitting the calculated concentrations of PDA, (1), (3), and (1') to the empirical concentrations of the corresponding compounds up to the reaction time of $30 \mathrm{~min}$ (see, Figure $3 \mathrm{a}$ ). Here, the concentration of (2) was neglected. The calculated concentrations of each compound were obtained by solving a set of eq $1-6$ as a function of reaction time by substituting eight arbitrary parameter values of $k_{10}, k_{-10}, k_{30}, k_{-30}, k_{10}^{\prime}, k_{10}^{\prime}, k_{30}^{\prime}$, and $k_{-30}$ and zero for the concentration of (2). Then, by utilizing the rough values of the eight rate constants, the rest of four constants, $k_{20}, k_{-20}, k_{20}^{\prime}$, and $k_{-20}^{\prime}$ were determined by comparing the empirical data for the reaction time in the range from 30 to $120 \mathrm{~min}$. At the same time the eight constants already estimated were adjusted so as to fit better to the empirical data in overall 
reaction time (the best-fitted curves were typically drawn by the least square method and pictured in Figure 3a). The twelve constants thus obtained were averaged with those estimated by using other AP data.

Based on the above rate constants, six catalyst constants $\left(k_{1}, k_{-1}, k_{2}, k_{-2}, k_{3}\right.$, and $\left.k_{-3}\right)$ in the presence of an acid were estimated and averaged similarly by fitting the calculated data to those of the AP 6 and 7 reactions. The rate constants and catalysts constants for the reaction with EDA were also estimated in the similar manner by using AE1-4 data as a representative (Figure $4 \mathrm{a}$ shows the best-fitted curves with the use of AE1 data).

\section{RESULTS AND DISCUSSION}

Reactions of various ketones with PDA were carried out to know reactivity dependence of the functional groups on the chemical structures of the ketones. Figure 1 shows the decrease in the concentrations of PDA determined by ${ }^{13} \mathrm{C}$ NMR for various reaction systems. Note that $[\mathrm{PDA}] /[\mathrm{PDA}]_{0}$ in this figure denotes the ratio of the concentration of unreacted PDA to the initial PDA concentration. From this figure, it is easily found that the reaction rate decreases with an increase in the number of carbons in alkyl groups of the ketones and in the case of the reaction with diisopropyl ketone, PDA remained unreacted even after $2 \mathrm{~h}$ at $50^{\circ} \mathrm{C}$. This behavior can be

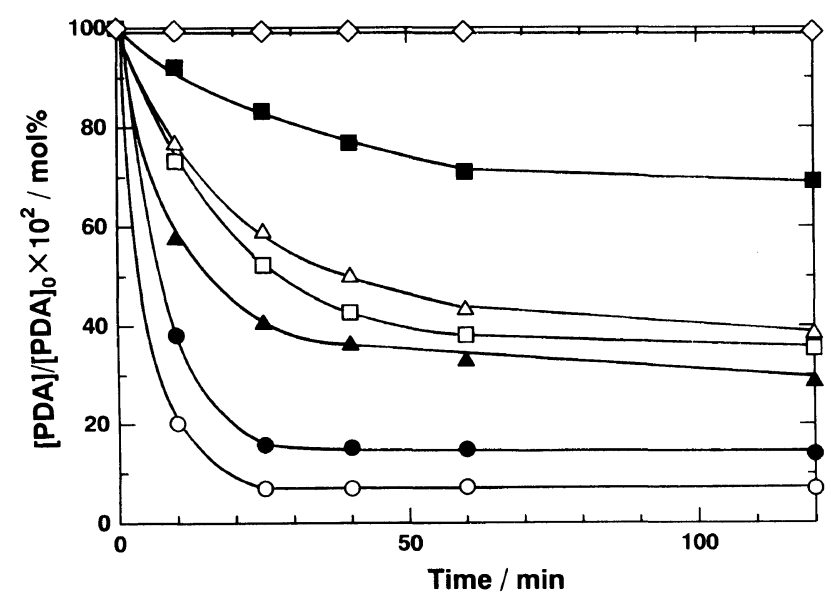

Figure 1. Dependence of chemical structures of ketones on rates of decrease in concentrations of PDA for reactions with various ketones (KP1-7): ○, (KP1); O, (KP2); $\triangle$, (KP3); $\Delta,(\mathrm{KP} 4) ; \square,(\mathrm{KP} 5), \square$ (KP6); $\diamond,(\mathrm{KP} 7)$. explained by the steric hindrance of the alkyl groups.

In order to clarify the reaction mechanism in details by ${ }^{13} \mathrm{C}$ NMR analysis, the reaction of acetone with PDA was chosen as that of a plausible combination of a ketimine and a diamine by considering the relatively fast reactivity and asymmetry of the chemical structure of PDA, expecting to give rise to well-splitted peaks of $\mathrm{CH}$ and $\mathrm{CH}_{2}$ carbons even when the amino groups attached to these carbons reacted, compared with the case of symmetrical EDA containing two $\mathrm{CH}_{2}$ carbons.

A series of the reactions of acetone with PDA (AP1-7) and with EDA (AE1-4) were carried out with or without an acid catalyst. Table II lists the assignment of ${ }^{13} \mathrm{C}$ nuclei for each compound by ${ }^{13} \mathrm{C}$ NMR. And Table III compiles the rate and catalyst constants relating to the elementary reactions for these AP and AE estimated according to the procedures in EXPERIMENTAL.

The molar fraction of each compound has a tendency to level off after $80 \mathrm{~min}$ at $40^{\circ} \mathrm{C}$ (Figure $2 \mathrm{~b}$ ), indicating that the reaction reaches an equilibrium state. With increasing the temperature the concentration of (3) in equilibrium decreases while those of (1) and (2) increases

Table II. Assignment results of reaction products from acetone and PDA

\begin{tabular}{llllll}
\hline & & \multicolumn{4}{c}{ Chemical shifts/ppm } \\
\cline { 3 - 6 } & Structure & $\mathrm{CH}_{2}$ & $\mathrm{CH}$ & $\mathrm{C}=\mathrm{N}$ & $\mathrm{C}$ \\
\hline & $\mathrm{CH}_{3}$ & & & \\
PDA & $\mathbf{H}_{\mathbf{2}} \mathrm{NCH}_{\mathbf{2}} \mathrm{CHNH}_{\mathbf{2}}$ & 50.8 & 49.4 &
\end{tabular}

(1)

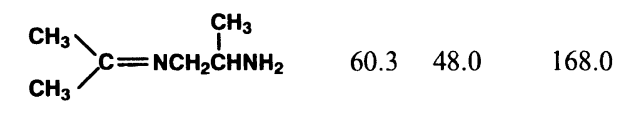

$\left(1^{\prime}\right)$

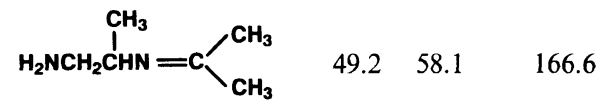

(2)

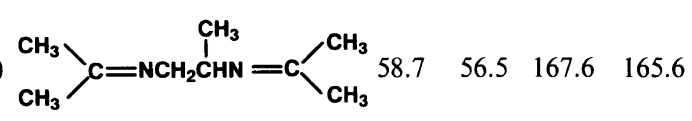

(3)

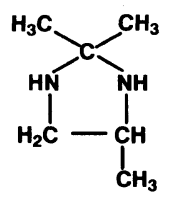

Table III. Rate and catalyst constants of elementary reactions

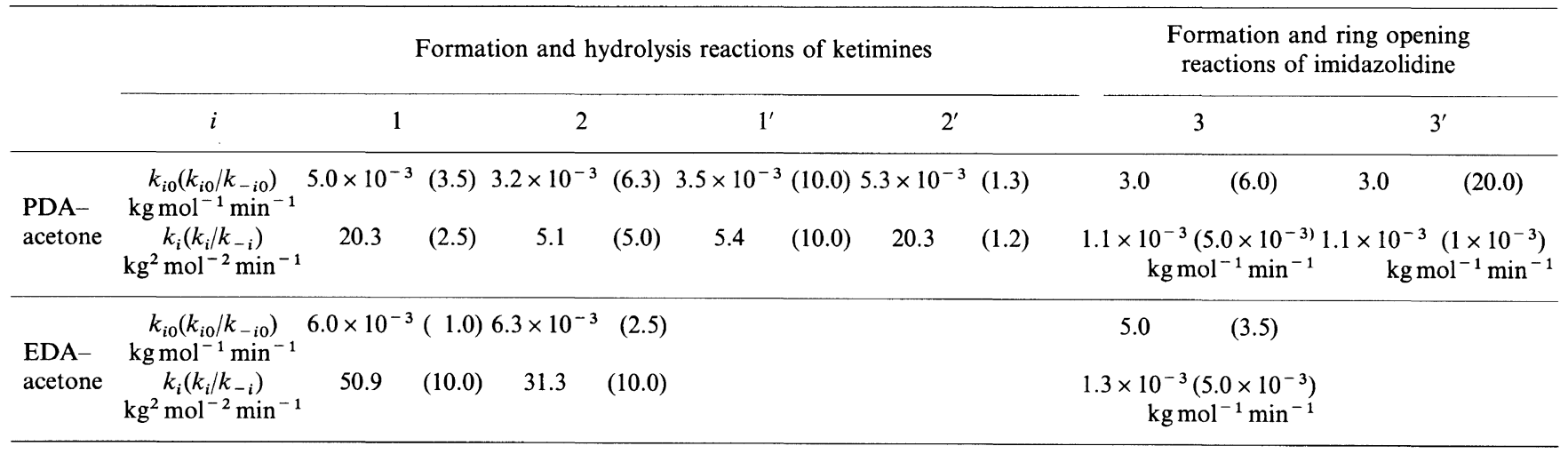


(a)

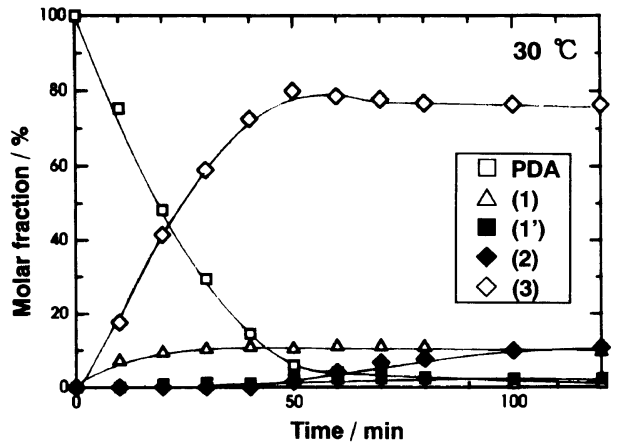

(b)

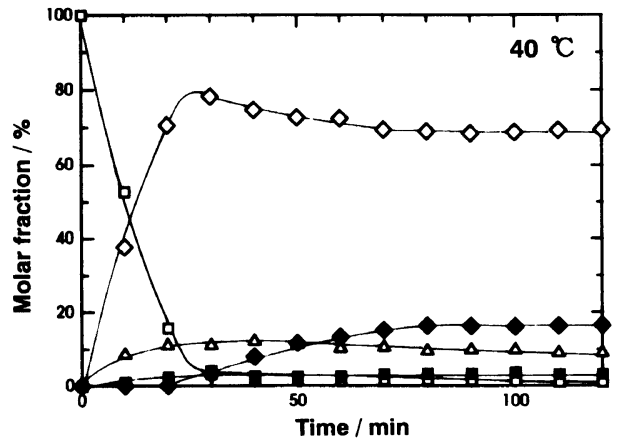

(c)

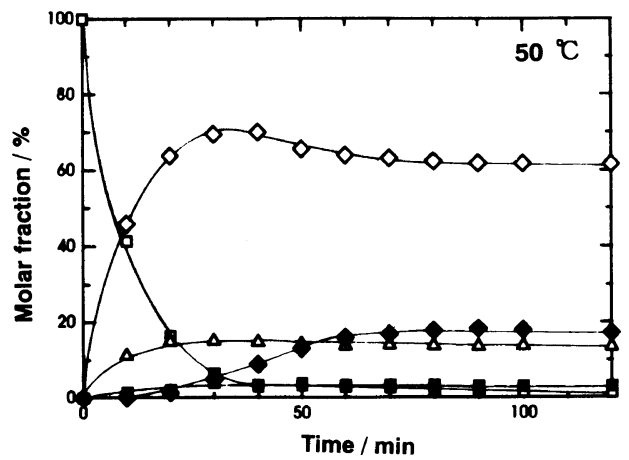

Figure 2. Time-conversion curves of each compound for reactions of acetone with PDA at different reaction temperatures (AP1-3): (a) $30^{\circ} \mathrm{C}$ (AP1); (b) $40^{\circ} \mathrm{C}$ (AP2); (c) $50^{\circ} \mathrm{C}(\mathrm{AP} 3)$

slightly. Soon after the reaction (1) was formed first in proportion to the rate of $k_{10}$ (the formation of $\left(\mathbf{1}^{\prime}\right)$ is relatively slow due to $k_{10}>k_{10}^{\prime}$ ) and then consumed rapidly to form (3) rather than (2) because of the extremely fast formation reaction of (3) subject to water catalysis $\left(k_{30} \gg k_{20}\right)$. After this reaction reached an equilibrium state, (1) began to accumulate, as a consequence, leading to the formation of (2). The relatively large equilibrium constant of $k_{20} / k_{-20}(=6.3)$ for (2) formation may be ascribed to the steric hindrance of the methyl group attached to the methyne carbon which reduces susceptibility of the weakly electronegative $\mathrm{C}=\mathrm{N}$ group of (2) toward $\mathrm{H}_{2} \mathrm{O}$. From the same reason the relation that $k_{20} / k_{-20}(=6.3)$ is close to $k_{10}^{\prime} / k_{-10}^{\prime}(=10.0)$. On the contrary, the relation that $k_{10} / k_{-10} \quad(=3.5)<k_{20} / k_{-20} \quad(=6.3) \quad$ and $\quad k_{20}^{\prime} / k_{-20}^{\prime}$ $(=1.3)<k_{20} / k_{-20}(=6.3)$ is realized because of the absence of the steric hindrance of the methyl group.

The reason why the concentration of $\left(\mathbf{1}^{\prime}\right)$ remained lower compared to that of (2) can be explained kinetically; (1') was not formed favorably compared to (1) because of $k_{10}>k_{10}^{\prime}$. In addition, this compound was not accumulating even after the concentration of (3) became equilibrated due to the large equilibrium constant of (a)

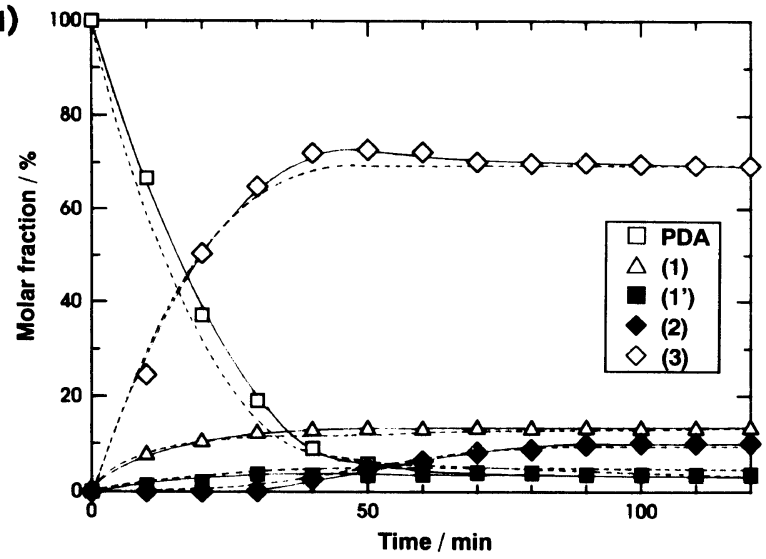

(b)

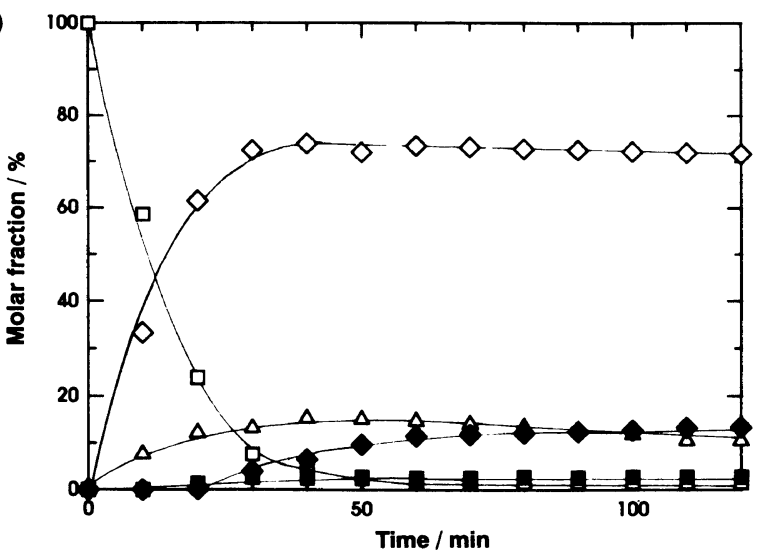

Figure 3. Time-conversion curves of each compound for reactions of acetone with PDA for different initial concentration ratios of acetone to PDA, [acetone $]_{0} /[\mathrm{PDA}]_{0}$ (1.8 (a) (AP4) and 2.4 (b) (AP5), respectively). In the figure (a) the best-fitted calculated curves (the broken curves) are also drawn.

$k_{30}^{\prime} / k_{-30}^{\prime}(=20.0)$ compared to $k_{30} / k_{-30}(=6.0)$. Although the reason for the considerable large $k_{30}^{\prime} / k_{-30}^{\prime}$ value is not certain yet, it may be associated with basestrengthening effect of the electron donor group of the methyl group attached to the methylene carbon of (3). Thus it is not unreasonable to deduce that the main reaction pathway in this reaction system is in the order of the formation; $(\mathbf{1}) \rightarrow(\mathbf{3}) \rightarrow(\mathbf{2})$.

Figures $2 \mathrm{~b}, 3 \mathrm{a}$, and $3 \mathrm{~b}$ show how the molar concentration ratio of acetone to PDA ([acetone $]_{0} /[\mathrm{PDA}]_{0}$ ) affects the product composition at $40^{\circ} \mathrm{C}(\mathrm{AP} 2,4$, and $5)$. It is pictured that with increasing [acetone $]_{0} /[\mathrm{PDA}]_{0}$, the slight increase in the concentration of (2) in the equilibrium state was observed. This behavior can be comprehended by the relatively large $k_{30}$ and $k_{30} / k_{-30}$ values.

In the case of the reactions of acetone with EDA, the reaction proceeded in the similar path to that with PDA (the reaction products from acetone and EDA consist of (4), (5), (6), and water including the unreacted EDA (Scheme 3)). Figures $4 a$ and $b$ show dependence of molar fractions of each compound formed on the masking ratio of acetone to $\mathrm{EDA}$, [acetone $]_{0} /[\mathrm{EDA}]_{0}$ at $40^{\circ} \mathrm{C}$. It is shown that (4) was formed first and successively (6) and (5) were formed in this order. By comparing Figures 3 and 4, the main difference between the reaction of acetone with PDA and with EDA resides in the greater concentration of the imidazolidine, (3) for the former reac- 
(a)

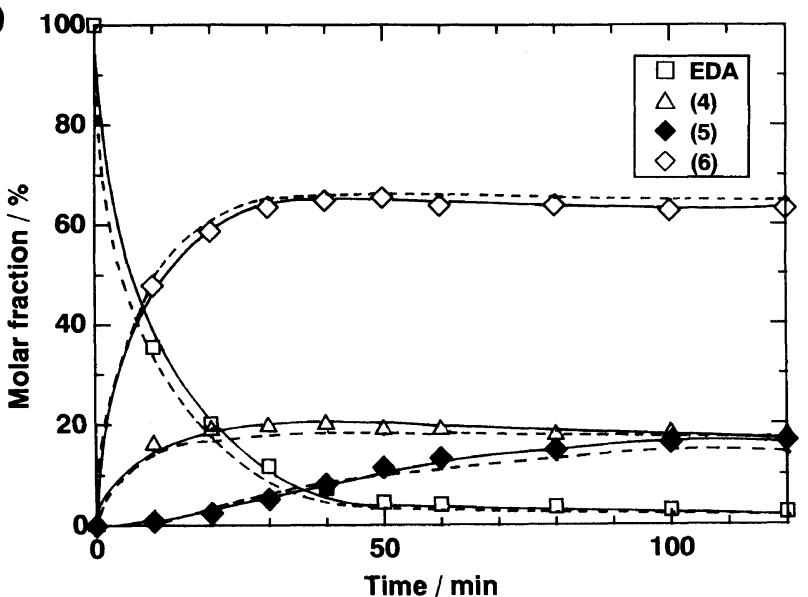

(b)

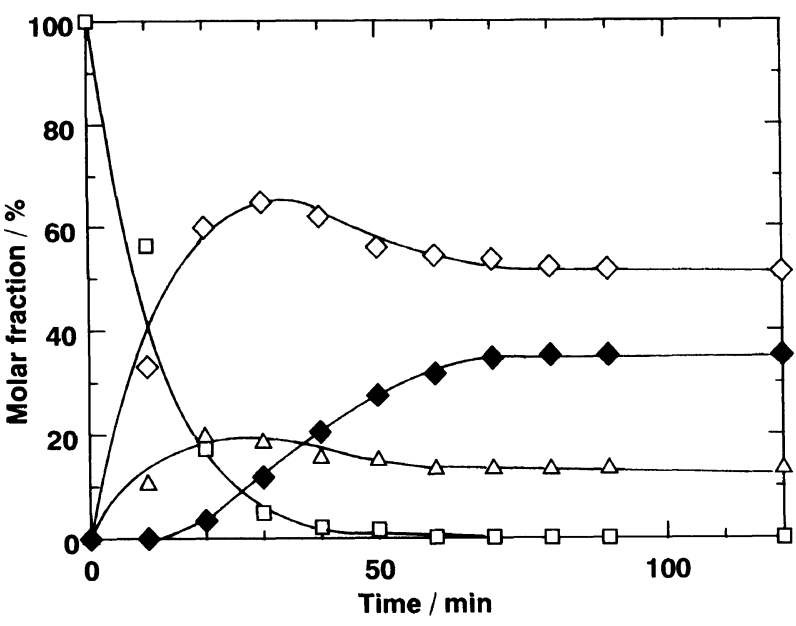

Figure 4. Time-conversion curves of each compound for reactions of acetone with EDA for different initial concentration ratios of acetone to EDA, [acetone $]_{0} /[\mathrm{EDA}]_{0}$ (1.4 (a) (AE1) and 2.8 (b) (AE2), respectively). In the figure (a) the best-fitted calculated curves (the broken curves) are also drawn.

tion system than (6), leading to the lower concentration of (2) against (5) mainly due to the relatively small equilibrium constant of $k_{30} / k_{-30}$ for (3).

In the direct synthesis of PUU (DSPUU reaction) where the demasking reactions including the hydrolysis reactions of (4) and (5) as well as the ring opening reaction of $(\mathbf{6})$ become important, the ring opening reaction is dominant $\left(k_{-30}=1.43 \mathrm{~kg} \mathrm{~mol}^{-1} \mathrm{~min}^{-1}\right)$. These three compounds were reported in the previous paper ${ }^{1}$ to play the roll of the catalysts for the side reaction of NCOs with water and an attempt was made there to reduce the by-product by increasing the rate of the hydrolysis reaction of (4) and (5) as well as the water-catalyzed ring opening of (6). The reason for the minor contribution of water is directly associated with the slow hydrolysis rates of (4) and (5) $\left(k_{-10}\right.$ and $k_{-20}$ in Table III) compared with that of acetic acid (described later).

Figure 5 shows the plots of molar fractions of each compound from the reaction of acetone with PDA (AP6 and 7) at $40^{\circ} \mathrm{C}$ in the presence of the acid. By comparing the composition of the reaction products in the equilibrium state shifted to the increase in the concentration of (2) and the decrease of that of (1). Compound (3) remained almost unchanged. The catalyst constants such as $k_{1}$ and $k_{2}$ definitely suggest that the dehydration reaction forming the ketimine group is subject (a)

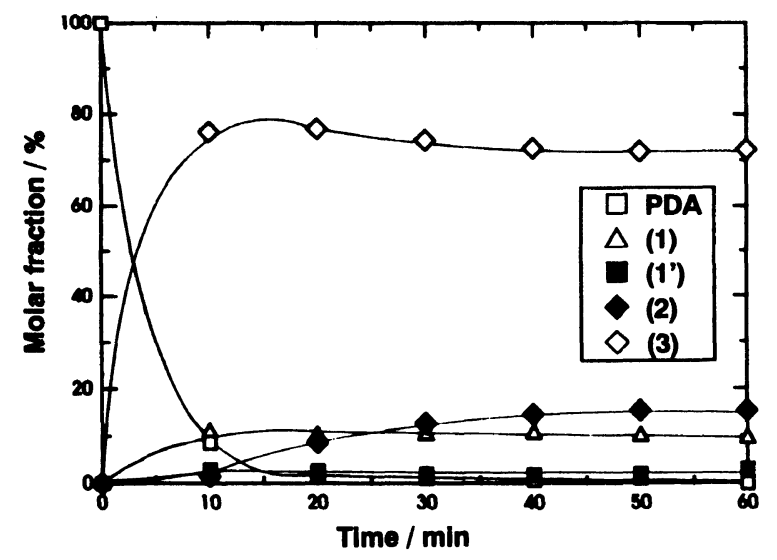

(b)

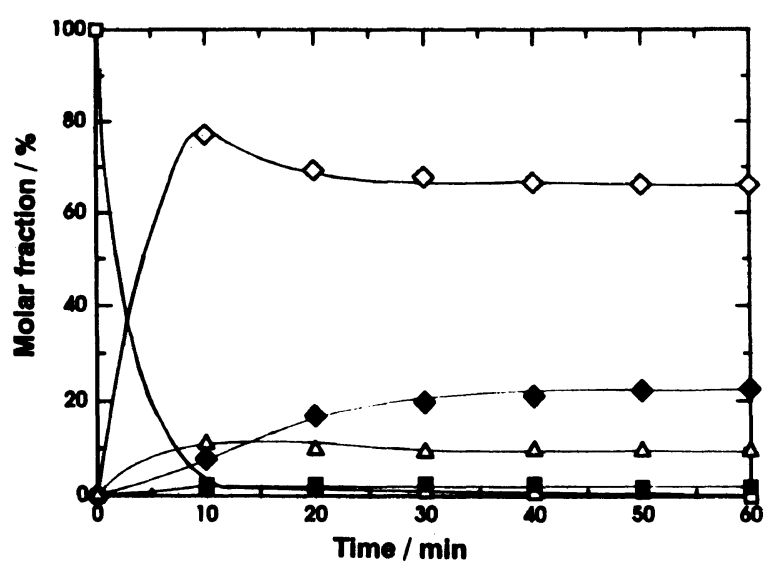

Figure 5. Time-conversion curves of each compound for reactions of acetone with PDA in the presence of the acid for different initial concentration ratios of acetone to PDA, [acetone $]_{0} /[\mathrm{PDA}]_{0}(2.5$ (a) (AP6) and 4.9 (b) (AP7), respectively). Symbols are the same as those denoted in Figure 3.

to acid catalysis, explaining the composition shift of (1) and (2). The reverse reaction is also acid-catalyzed by the stabilization of the protonated ketimine, ${ }^{3}$ although the catalytic effect is weaker than the dehydration reaction (see for example, $k_{1} / k_{-1}=2.5$ in Table III). This enables to shorten the equilibrated time. The reason why the equilibrated concentration of (3) was almost unchanged is associated with the small $k_{3}$ while the ring opening reaction is subject to weak acid catalysis $\left(k_{-3}\right)$. Similar tendencies were obtained in the case of acetone-EDA reaction; the catalyst constants of (4) $\left(k_{1}=50.9 \mathrm{~kg}^{2} \mathrm{~mol}^{-2} \mathrm{~min}^{-1}\right)$ and of (5) $\left(k_{2}=31.3 \mathrm{~kg}^{2}\right.$ $\mathrm{mol}^{-2} \mathrm{~min}^{-1}$ ) are both larger than the corresponding values for acetone-PDA reactions and the relatively large equilibrium constants $\left(k_{1} / k_{-1}=k_{2} / k_{-2}=10.0\right)$ were obtained. In the DSPUU reaction with the acid catalyst, the acid-catalyzed hydrolysis reactions of (4) and (5) will come into effect $\left(k_{-1}=5.09\right.$ and $k_{-2}=3.13 \mathrm{~kg}^{2} \mathrm{~mol}^{-2}$ $\left.\min ^{-1}\right)$ in addition to the acid-catalyzed ring opening reaction of (6) $\left(k_{-3}=0.26 \mathrm{~kg} \mathrm{~mol}^{-1} \mathrm{~min}^{-1}\right)$.

It is of interest, to compare the magnitude of the above catalyst constants with those for the analogous reactions in water. The catalyst constants for the latter are reported to be far larger by over sixfold range. ${ }^{4}$ This may be associated with comparably larger strength of the acid catalyst, $\mathrm{H}^{+}$than that of $\mathrm{H}_{3}^{+} \mathrm{N}-\mathrm{R}$ for the former case. In addition solvation of water to carbinolamine inter- 
mediates and/or ketimine groups, leading to stability of these compounds, may also be related to these differences.

Acknowledgments. The authors are grateful to Director, Dr. Kunihiko Okajima, Dr. Yasuhiro Nakano, and Dr. Nobuchika Tamura, of Central Laboratory (Takatsuki), Asahi Chemical Industry Co., Ltd. for their valuable comments and useful advises. And the authors also wish to thank Prof. Sakakibara, Department of Chemistry, Yokohama City University for performing $a b$ initio calculations of the conformation enthalpy of the addition compounds.

\section{REFERENCES AND NOTES}

1. E. Yamazaki, H. Hanahata, J. Hiwatari, and Y. Kitahama, Polym. J., 29, 811 (1997)
2. Y. Nakano, E. Yamazaki, H. Hanahata, K. Okajima, and Y. Kitahama, Bull. Chem. Soc. Jpn., 70, 1185 (1997).

3. W. P. Jencks, Prog. Phys. Org., 2, 63 (1964).

4. W. P. Jencks, J. Am. Chem. Soc., 81, 475 (1959).

5. T. H. Fife and A. M. Pellino, J. Am. Chem. Soc., 23, 3062 (1980).

6. By ab initio MO method (Gaussian 92 Rev. G.3 19-May-1994) enthalpies of (i) a mixture of EDA and acetone, (ii) an intermediate, $N$-(1-hydroxy-1-methyl ethyl)ethanediamine, (iii) a mixture of $N$-isopropylideneethylenediamine and water were calculated on 3-61G* level. The enthalpy difference between (i) and (ii) is $-0.14 \mathrm{kcal} \mathrm{mol}^{-1}$ and that between (ii) and (iii) $12.6 \mathrm{kcal} \mathrm{mol}^{-1}$, clearly suggests that the rate limiting step is the dehydration reaction. For the reverse reaction the hydrolysis reaction from a ketimine group must be an another limiting step.

7. G. D. Christian, "Analytical Chemistry," Part I, John Wiley \& Sons, Inc., New York, N.Y., 1986. 